\title{
The Impact of Open Vs. Closed Blood Collection on Specimen Quality, Health Care Worker Safety, \& Work Efficiencies, at a Tertiary Care Centre in South India
}

\author{
Sankar S. ${ }^{1}$, Jayalakshmy P.L. ${ }^{2}$, Jim Joe ${ }^{3}$, Deepa S. ${ }^{4}$ \\ 1,2,4 Department of Pathology, Government Medical College, Kottayam, Kerala, India. \\ ${ }^{3}$ Department of Biochemistry, Government Medical College, Kottayam, Kerala, India.
}

\section{ABSTRACT}

\section{BACKGROUND}

In the present era of automation, the quality of laboratory specimens is critical towards the delivery of accurate and useful results. The mode of collection of the sample is one such variable. Proper collection and handling of blood samples prevent erroneous results, reduce turnaround time and ensure safety of healthcare workers and patients. The study purpose is to compare open and closed systems of blood collection and the impact of closed collection system in the reduction of pre analytical errors and promoting health care worker safety.

\section{METHODS}

This is a prospective comparative study and it was conducted on blood samples collected in the Outpatient Department of Government Medical College, Kottayam and preanalytical study variables were assessed at Departments of Haematology and Biochemistry. At the beginning of the study, the quality and the quantity of specimen, result accuracies and healthcare safety parameters were assessed for 4778 samples using open blood collection system. This was followed by training of the phlebotomists for closed system of blood collection. The same parameters were studied for another 2508 blood samples collected via closed collection system by the same phlebotomists. The open blood collection system was carried out using non vacuum tubes (Plain and K3 EDTA), $5 \mathrm{ml}$ syringe and 23G needles and closed blood collection system used BD vacutainer (K2 EDTA and serum gel tubes), Eclipse тм safety $22 \mathrm{G}$ needles and pronto тм reusable safety holders. The study was conducted from 01-01-2021 to 31-03-2021.

\section{RESULTS}

The specimen quality errors namely fibrin mass, strands, haemolysis, recentrifugation, and insufficient volume in biochemistry lab were significantly reduced with introduction of closed collection system. In haematology lab, closed collection system reduced incidence of clotted sample, insufficient volume accompanied by significant reduction in platelet and WBC differential flags. Closed collection system also reduced occurrence of blood smeared containers and blood spillage on test requisition forms, hence improving safety of health care personnel.

\section{CONCLUSIONS}

The study establishes a significant reduction in pre-analytical errors with closed blood collection system, prevents test cancellation and improved workflow efficiency.

\section{KEY WORDS}

Accuracy, Blood Collection Systems, Errors, Phlebotomist, Preanalytical, Spillage, Variables.
Corresponding Author:

Dr. Jayalakshmy P.L.,

C-Block, Department of Pathology,

Government Medical College,

Kottayam-686008, Kerala, India.

E-mail: jayafloyyd@gmail.com

DOI: $10.14260 / j e m d s / 2022 / 71$

How to Cite This Article:

Sankar S, Jayalakshmy PL, Joe J, et al. The impact of open vs. closed blood collection on specimen quality, health care worker safety, \& work efficiencies, at a tertiary care centre in south India. J Evolution Med Dent Sci 2022;11(02):369-374, DOI: 10.14260/jemds/2022/71

Submission 20-01-2022,

Peer Review 25-01-2022,

Acceptance 04-02-2022,

Published 07-02-2022.

Copyright (c) 2022 Sankar S. et al. This is an open access article distributed under Creative Commons Attribution License [Attribution 4.0 International (CC BY 4.0)] 


\section{BACKGROUND}

Advances in medical technology have led to an increased reliance of medical decision making on lab results. In a paper published by Mayo clinic in 1996, the author states "We know that, although the laboratory represents a small percentage of medical centre costs, it leverages $60-70$ percent of all critical decisions for example admission, discharge and therapy." ${ }^{1}$ The aim of every lab today is to provide timely and accurate results. Lab Automation has played a critical part in improving turnaround time (TAT) and standardizing analytical processes. However, every machine is still dependent on the quantity and quality of the specimen presented. It is a well-established fact that preanalytical errors are influenced by a variety of reasons including specimen collection techniques, transportation, interfering substances, and patient factors. ${ }^{2-5}$ Further, type of collection and collection containers are known to impact the specimen quality and result outcomes. ${ }^{6}$ Several studies conducted in the past have demonstrated improvement of specimen quantity and quality after shifting from open to closed collection system. Open collection systems are known to cause high incidence of haemolysis, blood spillages and exposure of potentially infectious materials to the patients and health care workers (HCW). Incidence of under filled specimen containers are known to be more than 10 times higher in open collection system, leading to significant preanalytical errors, like cell shrinkage especially in EDTA specimens. ${ }^{6}$ On the other hand, closed collection system practices are associated with reduced specimen rejections, improved overall workflow efficiencies, cost benefits due to minimal repeat testing \& re-draws, lesser instrument maintenance and enhanced HCW (healthcare worker safety). ${ }^{6-7}$ While a lot of studies have demonstrated improvement of specimen quality with the use of closed collection, its direct impact on result accuracies is often missed in most of the studies.

The purpose of this study is to monitor error/rejection rates \& HCW safety indices with open and closed blood collection devices in the outpatient department (OPD) of a busy government hospital to understand the quantum of impact of practice change from open to closed systems on specimen quality, result accuracy, work efficiencies and HCW safety.

\section{METHODS}

This is a prospective comparative study and it was designed to compare the impact of open collection system, Group A: Open collection by $5 \mathrm{ml}$ syringe, $23 \mathrm{G}$ needles and non-vacuum tubes (Plain serum $2 \mathrm{ml}$ tubes \& K3 EDTA $2 \mathrm{ml}$ tubes) vs closed collection system, Group B: BD Vacutainer® K2 EDTA $2 \mathrm{ml}$, serum gel tubes $5 \mathrm{ml}$, Eclipse ${ }^{\mathrm{TM}}$ safety needles $22 \mathrm{G}$, and Pronto $^{\mathrm{TM}}$ reusable safety holders on the specimens collected in the OPD of Govt Medical College, Kottayam. At the beginning of the study, the quality and the quantity of specimen, result accuracies and healthcare safety parameters were assessed for 4778 samples using open blood collection system. This was followed by training of the phlebotomists for closed system of blood collection. The same parameters were studied for another 2508 blood samples collected via closed collection system by the same phlebotomists. The study was approved by the Institutional Ethics and Scientific Review Committee and it was conducted from 01-01-2021 to 31-03-2021. The study was designed for sequential enrolment of patients with baseline assessments in open collection phase followed by staff trainings on closed collection phase ( 8 phlebotomists) and end line assessment on closed collection with no change in the specimen collection staff.

\section{Study Setting}

The specimens collected between 8 am to $2 \mathrm{pm}$ were transported manually to haematology and biochemistry departments where they were assessed for quantity \& quality of specimen, result accuracies and HCW safety parameters. All specimens were inspected visually to record number of blood-stained requisition forms and containers \& spillage in lab. Data thus collected was transcribed into data register at the end of each day.

\section{Haematology}

Specimens were visually inspected for clot and volume insufficiency for the impact i.e., sample rejected or tested but report released with a comment

- $\quad$ Platelets - All specimens flagged by the instrument were reflexed to manual smear and discrepancies from machine results were recorded and analysed.

- WBC differential count - Approximately 15 specimens flagged as high/low for differential counts were selected randomly on a daily basis and reflexed to manual slides. The data was recorded and analysed for discrepancy between manual and machine results.

\section{Biochemistry}

Specimens were inspected visually for fibrin strands, fibrin mass, haemolysis, volume insufficiency. Haemolysis grading was done using haemolysis chart.

\section{Inclusion Criteria}

All venous blood samples collected between 08:00 am to 02:00 pm at the OPD of biochemistry and haematology departments.

\section{Exclusion Criteria}

All samples collected from IPD, OPD samples collected between $2 \mathrm{pm}$ to $8 \mathrm{am}$, specimens other than venous and specimens collected by any other method except study methodology (syringe or closed system) were excluded from study analysis.

\section{Statistical Analysis}

Data collected in the study was presented as number of errors, \% of errors and \% change in errors. The statistical significance was analysed using unpaired t test (two tailed). 


\section{RESULTS}

On comparison with open collection in the Department of Biochemistry, specimen quality errors (Table 1) like fibrin mass, fibrin strands, haemolysis, re-centrifugation and insufficient volume to perform test were significantly reduced with $\mathrm{p}$ value $<0.01$ in closed blood collection system along with the reduction in "report released with comments".

On comparison with open collection (Table 1), the percentage of blood smeared containers and blood spillage on requisition slips in laboratory ( $p$ value $<0.01$ ) were reduced to zero $(0.0 \%)$ in the closed blood collection system, thereby improving the HCW safety by reducing the exposure to blood.

In the Department of Haematology, specimen collection by closed collection methodology resulted in significant improvement in specimen quality, (reduction in incidence of clotted samples \& insufficient blood volume ( $p$ value $<0.01$ ) result accuracy and workflow efficiency (significant reduction in platelet and WBC differential flags ( $p$ value $<0.01$ ). Specimen collection by closed collection also reduced the risk of contamination by reducing the incidence of blood smeared containers and blood spillage on requisition slips ( $\mathrm{p}$ value < 0.01) (Table 2).

\begin{tabular}{|c|c|c|c|c|c|c|c|}
\hline \multirow{2}{*}{\multicolumn{2}{|c|}{ Biochemistry }} & \multicolumn{2}{|c|}{$\begin{array}{c}\text { Open } \\
\text { Collection - } \\
\mathbf{n}=\mathbf{3 4 2 7}\end{array}$} & \multicolumn{2}{|c|}{$\begin{array}{c}\text { Closed Blood } \\
\text { Collection - } \\
n=1474\end{array}$} & \multirow{2}{*}{ 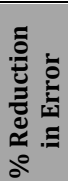 } & \multirow{2}{*}{$\mathbf{p}$} \\
\hline & & $\begin{array}{l}\text { No. of } \\
\text { Errors }\end{array}$ & $\%$ & $\begin{array}{l}\text { No. of } \\
\text { Errors }\end{array}$ & $\%$ & & \\
\hline \multirow{6}{*}{$\begin{array}{l}\text { Specimen } \\
\text { quality }\end{array}$} & Fibrin mass & 258 & $7.5 \%$ & 11 & $0.7 \%$ & $6.8 \%$ & $<0.01$ \\
\hline & Fibrin strands & 272 & $7.9 \%$ & 111 & $7.5 \%$ & $0.4 \%$ & $<0.01$ \\
\hline & Moderate haemolysis & 151 & $4.4 \%$ & 0 & $0.0 \%$ & $4.4 \%$ & $<0.01$ \\
\hline & Gross haemolysis & 97 & $2.8 \%$ & 0 & $0.0 \%$ & $2.8 \%$ & $<0.01$ \\
\hline & Re-centrifugation & 230 & $6.7 \%$ & 0 & $0.0 \%$ & $6.7 \%$ & $<0.01$ \\
\hline & $\begin{array}{l}\text { Insufficient volume to } \\
\text { perform test }\end{array}$ & 204 & $5.9 \%$ & 0 & $0.0 \%$ & $5.9 \%$ & $<0.01$ \\
\hline \multirow{3}{*}{$\begin{array}{l}\text { Report } \\
\text { released } \\
\text { with } \\
\text { comment }\end{array}$} & Fibrin thread/mass & 530 & $15.4 \%$ & 122 & $8.20 \%$ & $7.2 \%$ & $<0.01$ \\
\hline & Haemolysis & 248 & $7.2 \%$ & 0 & $0.0 \%$ & $7.2 \%$ & $<0.01$ \\
\hline & Insufficient volume & 204 & $5.9 \%$ & 0 & $0.0 \%$ & $5.9 \%$ & $<0.01$ \\
\hline \multirow{3}{*}{ HCW safety } & $\begin{array}{l}\text { Blood smeared } \\
\text { containers }\end{array}$ & 218 & $6.3 \%$ & 0 & $0.0 \%$ & $6.3 \%$ & $<0.01$ \\
\hline & $\begin{array}{l}\text { Blood spilled on } \\
\text { requisition slips }\end{array}$ & 255 & $7.4 \%$ & 0 & $0.0 \%$ & $7.4 \%$ & $<0.01$ \\
\hline & $\begin{array}{c}\text { Blood spillage in } \\
\text { laboratory }\end{array}$ & 15 & $0.4 \%$ & 0 & $0.0 \%$ & $0.4 \%$ & $<0.01$ \\
\hline
\end{tabular}

\begin{tabular}{|c|c|c|c|c|c|c|c|}
\hline \multirow{2}{*}{\multicolumn{2}{|c|}{ Haematology }} & \multicolumn{2}{|c|}{$\begin{array}{c}\text { Open } \\
\text { Collection - } \\
\mathbf{n}=1351\end{array}$} & \multicolumn{2}{|c|}{$\begin{array}{c}\text { Closed Blood } \\
\text { Collection - } \\
\text { n = } 1034\end{array}$} & \multirow{2}{*}{ 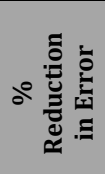 } & \multirow{2}{*}{$\mathbf{p}$} \\
\hline & & $\begin{array}{l}\text { No of } \\
\text { Errors }\end{array}$ & $\%$ & $\begin{array}{l}\text { No of } \\
\text { Errors }\end{array}$ & $\%$ & & \\
\hline \multirow{2}{*}{$\begin{array}{l}\text { Specimen } \\
\text { quality }\end{array}$} & Clotted Samples & 27 & $2.0 \%$ & 0 & $0.0 \%$ & $2.0 \%$ & $<0.01$ \\
\hline & Insufficient volume & 05 & $0.4 \%$ & 0 & $0.0 \%$ & $0.4 \%$ & $<0.05$ \\
\hline \multirow{3}{*}{$\begin{array}{c}\text { WBC } \\
\text { differential } \\
\text { flags }\end{array}$} & $\begin{array}{l}\text { Total specimens } \\
\text { reflexed to slide }\end{array}$ & 390 & $29.0 \%$ & 110 & $10.7 \%$ & $18.3 \%$ & $<0.01$ \\
\hline & False high & 158 & $12.0 \%$ & 61 & $6.0 \%$ & $6.0 \%$ & $<0.01$ \\
\hline & False low & 232 & $17.0 \%$ & 49 & $4.7 \%$ & $12.3 \%$ & $<0.01$ \\
\hline \multirow{2}{*}{$\begin{array}{l}\text { Platelet } \\
\text { Flags }\end{array}$} & $\begin{array}{l}\text { Total specimens } \\
\text { Reflexed to slide }\end{array}$ & 301 & $22.0 \%$ & 87 & $8.4 \%$ & $13.6 \%$ & $<0.01$ \\
\hline & $\begin{array}{l}\text { False high } \\
\text { False Low }\end{array}$ & $\begin{array}{l}176 \\
125\end{array}$ & $\begin{array}{c}13.0 \% \\
9.0 \%\end{array}$ & $\begin{array}{l}41 \\
46\end{array}$ & & $\begin{array}{l}9.0 \% \\
4.6 \%\end{array}$ & $\begin{array}{l}<0.01 \\
<0.01\end{array}$ \\
\hline \multirow{3}{*}{ HCW Safety } & $\begin{array}{l}\text { Blood Smeared } \\
\text { Containers }\end{array}$ & 40 & $3.0 \%$ & 0 & $0.0 \%$ & $3.0 \%$ & $<0.01$ \\
\hline & $\begin{array}{l}\text { Blood spilled on } \\
\text { requisition slips }\end{array}$ & 86 & $6.0 \%$ & 1 & $0.1 \%$ & $5.9 \%$ & $<0.01$ \\
\hline & $\begin{array}{c}\text { Blood spillage in } \\
\text { laboratory }\end{array}$ & 0 & $0.0 \%$ & 0 & $0.0 \%$ & NA & NA \\
\hline
\end{tabular}
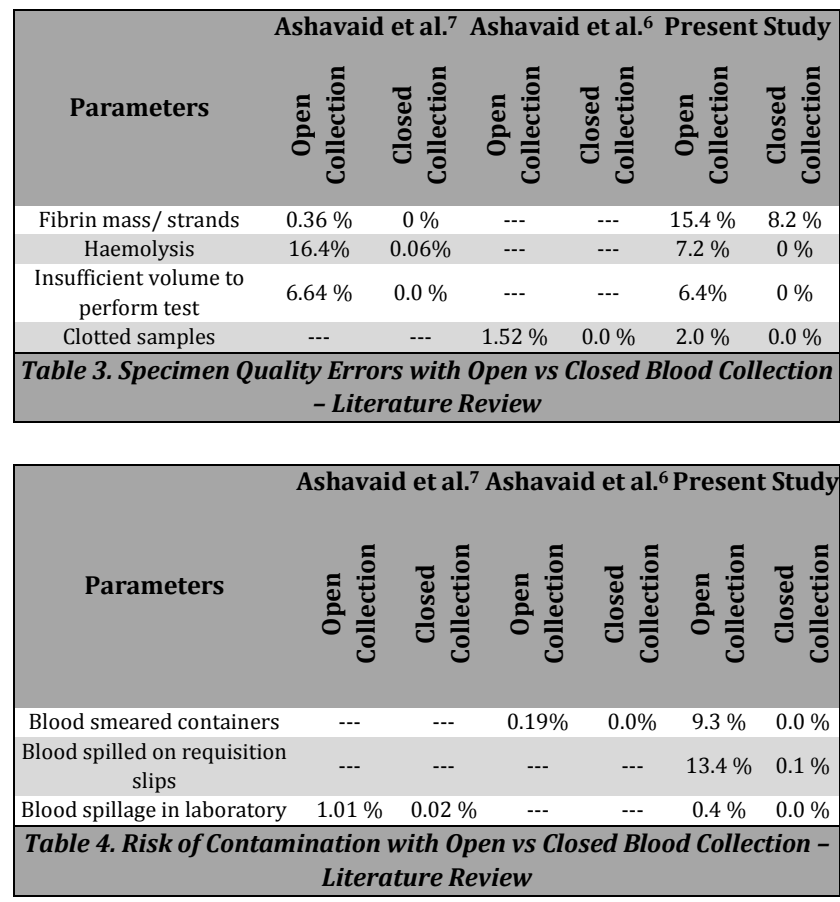

\section{DISCUSSION}

As shown in the above tables, all specimen quality and HCW safety indicators in haematology and biochemistry improved significantly with closed collection system.

\section{Fibrin Strands/Mass}

In the present study, we observed an incidence of postcentrifugation fibrin in $15.4 \%$ specimens (fibrin mass $7.5 \%$, strand $7.9 \%$ ) collected in open collection system and the same was reduced to $8.2 \%$ ( $\mathrm{p}$ value $<0.01$ ) in closed blood collection system. This was consistent with the study conducted by Ashavaid et al. ${ }^{7}$ (Table 3). Residual fibrin, long recognized as a possible interferent in the clinical laboratory, may be present because of improper mixing with clot activator or inadequate clotting time before centrifugation. It can be present either as a visible clot, which may physically occlude the instrument sampling probe or, more insidiously, as an invisible microfiber or as strand. Fibrin strands may directly affect some assays, especially immunoassays.8-11 Presence of latent fibrin in serum poses a risk of blocking analyser probe resulting in probe maintenance/replacement, and system breakdown, all of which were estimated to carry significant economic cost for the laboratory. ${ }^{12}$ It is thus important to mix the serum samples well and allow adequate clotting time. On the other hand, most of the hospital labs are faced with a challenge to provide results faster and often analytical quality gets sacrificed for a faster TAT. Despite installing high end automation and tracks, clotting time becomes the rate limiting step for most of the serum-based tests. While gel-based serum separator tubes offer faster clotting time, STAT or emergency tests may require an even faster TAT. In such situations, plasma specimen or a thrombin based rapid serum tubes (RST), may offer a better solution by reducing sample processing time. ${ }^{13}$ 


\section{Haemolysis}

The incidence of haemolysis was $7.2 \%$ in open collection system and the same was reduced to $0.0 \%(\mathrm{p}<0.01)$ in closed blood collection system. This was consistent with the study done by Ashavaid et al. ${ }^{6}$ (Table 3). Haemolysis could arise, whenever there is trauma to relatively fragile red blood cells, either during collection or after phlebotomy is completed. The common procedural errors that can cause haemolysis are forceful aspiration of the blood during syringe draw, injecting blood into the container using pressure, use of too small or too large bore needle, application of tourniquet for more than a minute, mixing additive tubes vigorously, rough handling during transport and frothing of blood caused by improper fit of the needle on a syringe. ${ }^{14}$ Furthermore, haemolysis also affects various chemical parameters such as potassium, creatine kinase due to the efflux of intracellular constituents and affects the test results. ${ }^{7}$ Since, haemolysis is the major risk factor for the inaccurate test results and the incidence is higher in open collection system, it is advisable to go for closed blood collection system.

\section{Volume Related Issues}

It was observed that $5.9 \%$ of biochemistry samples and $0.4 \%$ of haematology samples had insufficient volume to perform one or more analysis in case of open collection method. In such instances, either specimen was redrawn, or the report was released with comment. As compared to the open collection system, the incidence of insufficient volume was reduced to $0.0 \%$ ( $\mathrm{p}$ value $<0.01$ ) in closed blood collection system. This was consistent with other study done by Ashavaid et al.7 (Table 3). Underfilling or overfilling of tubes during open collection system can be an outcome of low volume draw because of selecting a wrong/difficult vein or a smaller syringe as well as due to the prejudices of the phlebotomist who believes certain tests can be performed with a very low volume of blood. It is important to point that adequacy of blood to additive ratio is important not just for sample quality but also for result accuracy. As an example, samples collected in overfilled EDTA tubes may clot faster whereas underfilled EDTA tubes may impact cell morphology and shrink RBCs which leads to decrease of mean corpuscular volume (MCV) and haematocrit values. ${ }^{15,16,17}$ This important factor is taken care by closed collection system by virtue of predetermined vacuum in the tubes which ensures adequate blood to additive ratio is maintained in each specimen.

\section{Clotted Samples}

The incidence of clotted specimens was $2.0 \%$ in open collection system and the same was reduced to $0.0 \%$ ( $\mathrm{p}$ value $<0.01$ ) in closed blood collection system. This was consistent with the other study done by Ashavaid et al. ${ }^{6}$ (Table 3). The presence of clots in EDTA samples can be explained primarily due to overfilling or improper mixing of the sample after syringe transfer. This could pose a major risk of erroneous results and analyser breakdown. ${ }^{6}$

\section{Report Released with Comment}

Under ideal circumstances, a specimen with a known preanalytical error should not be processed. However, in our lab with high sample volume and limited resources, it has proven to be difficult to reject the samples and request for repeat collection. Hence, the sample with concerns are tested but reported with riders mentioned in the comment. With the improvement in specimen quality, the incidence of "reports released with comments" was reduced significantly ( $\mathrm{p}$ value < 0.01 ) in closed collection which is reassuring to the lab as well as the clinician.

\section{WBC Differential Flags}

In general, the change in cell morphology could impact the ability of the cell counter to report/separate different populations of cells and hence raise a flag that indicates the same. This requires the laboratory to either report differential count using microscopy which increases the TAT. We observed that $29 \%$ of samples collected using an open method raised a differential flag, whereas the incidence of differential flag generation in case of closed collection was $10.7 \%$. The data clearly demonstrated that closed collection resulted in lower incidence of differential flagging. As described in the literature, decrease in WBC count not related to agglutination has been reported in samples containing excess of K3-EDTA (but not K2-EDTA) anticoagulant, resulting from insufficient blood drawn after venepuncture. ${ }^{18}$ This was consistent with our study results since $17.0 \%$ specimens showed false low WBC count in open collection system (k3 EDTA) when compared with closed collection system (4.7 \%). Also, the analyser can give pseuodoleukocytosis secondary to large platelet aggregates as these can mimic the size of WBC which could be the reason of the flags with closed collection system. ${ }^{19}$

\section{Platelet Flags}

Our study showed a high incidence of platelet flagging by analyser with open collection system (22\%) which was reflexed to slide for manual verification. The incidence of platelet flagging was reduced significantly $(8.4 \%$, p value < 0.01) with closed collection system. As described in the literature, K3 EDTA alters the platelet shape from discoid to spherical there by increasing the mean platelet volume (giant platelets). These giant platelets tend to be counted as either RBC or WBC by the analyser.20 This results in false low platelet count by the analyser which have to be verified manually there by increasing the TAT despite installing a high end five-part analyser. This was consistent with the present study, where we observed a high incidence of false low platelet count $(9.0 \%)$ because of platelet clumps in open collection and the same was reduced significantly with closed collection system ( $\mathrm{p}$ value $<0.01$ ).

\section{Health Care Worker Safety}

According to world health organisation, approximately two million HCW are exposed to blood borne pathogens per year. ${ }^{21}$ Laboratory workers are exposed to a wide range of hazards during collection and analysis of patient specimens. Procedures such as phlebotomy are considered as high-risk procedures due to a high probability of needle stick injury (NSI) which increase the likelihood of infection with human immunodeficiency virus (HIV) and hepatitis C virus (HCV). ${ }^{22}$ 
Syringe collections pose a great risk of NSI as well as contamination of requisitions and tube exteriors during the transfer of specimen from syringe to tube and during transportation. Blood-stained requisitions and tubes can be cause of transfer of infections when pathogens are shed in blood and contact transfer is an important route of transmission example of Covid-19.23

In present study, the incidence of blood exposure (blood smeared containers, blood spilled on request slips, blood spillage in laboratory) to HCW was $23.1 \%$ in open collection system and the same was reduced to $0.1 \%$ (p: < 0.01) with closed blood collection system. This was consistent with the study done by Ashavaid et al.6,7 (Table 4). Closed collection systems, by virtue of direct transfer of blood from vein to tube, protect the HCWs against risk of NSI and contact transfer of infections.

\section{CONCLUSIONS}

This study once again establishes that open collection systems are associated with a high incidence of preanalytical errors leading to probe blockage, inaccurate results, repeat samples, test cancellations and impaired workflow efficiencies despite a high level of automation. Such limitations can impact the adequacy and timeliness of treatment especially during situations of health care overload like infectious outbreaks (e.g.: Dengue, Covid-19) where the benefits of automation i.e., improved TAT and accuracy are most essential. Based on the observations in this study, it is evident that the use of an evacuated closed collection system for venous blood collection improved the sample quality, workflow efficiency and decreased the potential exposure of HCW to blood and blood borne pathogens. It also reinforces the need and urgency to shift to closed collection system in the face of the ongoing pandemic to ensure HCWs are protected enough to provide health care to others.

\section{Conflict of Interest}

The study was designed and conducted by the faculty of Government Medical College, Kottayam. The materials for the closed collection procedures were provided by Becton Dickinson India Pvt. Ltd.

\section{REFERENCES}

[1] Forsman RW. Why is the laboratory an afterthought for managed care organizations? Clin Chem 1996;42(5):8136.

[2] Ricos C, Garcia-Victoria M, de la Fuente B. Quality indicators and specifications for the extra-analytical phases in clinical laboratory management. Clin Chem Lab Med 2004;42(6):578-82.

[3] Tammen H. Specimen collection and handling: standardization of blood sample collection. Methods Mol Biol 2008;428:35-42.

[4] Witte DL, Vanness SA, Angstadt DS, et al. Errors, mistakes, blunders, outliers or unacceptable results: how many? Clin Chem 1997;43(8):1352-6.
[5] Bonini P, Plebani M, Ceriotti F, et al. Errors in laboratory medicine. Clin Chem 2002;48(5):691-8.

[6] Ashavaid T, Dandekar S, Khodaiji S, et al. Influence of method of specimen collection on various preanalytical sample quality indicators in EDTA blood collected for cell counting. Indian J Clin Biochem 2009;24(4):356-60.

[7] Ashavaid T, Dandekar S, Keny B, et al. Influence of blood specimen collection method on various preanalytical sample quality indicators. Indian J Clin Biochem 2008;23(2):144-9.

[8] Nosanchuk JS. False increases in troponin I attributable to incomplete separation of serum. Clin Chem 1999;45(5):714.

[9] Beyne P, Vigier JP, Bourgoin P, et al. Comparison of single and repeated centrifugation of blood specimens collected in BD closed blood collection tubes containing a clot activator for cardiac troponin I assay on the ACCESS analyzer. Clin Chem 2000;46(11):1869-70.

[10] Ooi DS, House AA. Cardiac troponin T in hemodialyzed patients. Clin Chem 1998;44(7):1410-6.

[11] Roberts WL, Calcote CB, De BK, et al. Prevention of analytical false positive increases of cardiac troponin I on the Stratus II analyzer. Clin Chem 1997;43(5):860-1.

[12] Erdal E, Mitra D, Khangulov V, et al. The economic impact of poor sample quality in clinical chemistry laboratories: results from a global survey. Ann Clin Biochem 2017;54(2):230-9.

[13] Devi MG, Ganji SB, Saad A, et al. Identification and corrective actions of preanalytical errors in clinical biochemistry laboratory of a pediatric tertiary care hospital: a two year study. Medpulse Int J Biochem 2018;5(2):67-73.

[14] Çuhadar S. Preanalytical variables and factors that interfere with the biochemical parameters: a review. OA Biotechnology 2013;2(2):19.

[15] Peterson P, Gottfried EL. The effects of inaccurate blood sample volume on prothrombin time (PT) and activated partial thromboplastin time (aPTT). Thromb Haemost 1982;47(2):101-3.

[16] Reneke J, Etzell J, Leslie S, et al. Prolonged prothrombin time and activated partial thromboplastin time due to under filled specimen tubes with $109 \mathrm{mmol} / \mathrm{L} \mathrm{(3.2 \% )}$ citrate anticoagulant. Am J Clin Pathol 1998;109(6):7547.

[17] McCall R, Tankersley C. Phlebotomy essentials. $6^{\text {th }}$ edn. Philadelphia: Wolters Kluwer Health 2016.

[18] Goossens W, van Duppen V, Verwilghen RL. K2 or K3 EDTA: the anticoagulant of choice in routine haematology? Clin Lab Haematol 2008;13(3):291-5.

[19] Zandecki M, Genevieve F, Gerard J, et al. Spurious counts and spurious results on haematology analysers: a review. Part II: white blood cells, red blood cells, haemoglobin, red cell indices and reticulocytes. Int J Lab Hematol 2007;29(1):21-41.

[20] Brigden M, Dalal B. Cell Counter-related abnormalities. Laboratory Medicine 1999;30(5):325-34.

[21] Ballout RA, Diab B, Harb AC, et al. Use of safetyengineered devices by healthcare workers for intravenous and/or phlebotomy procedures in healthcare settings: a systematic review and metaanalysis. BMC Health Serv Res 2016;16:458. 
[22] De Carli G, Abiteboul D, Puro V. The importance of implementing safe sharps practices in the laboratory setting in Europe. Biochem Med 2014;24(1):45-56.
[23] Zhang W, Du RH, Li B, et al. Molecular and serological investigation of 2019-nCoV infected patients: implication of multiple shedding routes. Emerg Microbes Infect 2020;9(1):386-9. 